See Article page 1818.

\section{Commentary: Eradication of epicardial pacing}

\author{
Henry M. Spotnitz, MD
}

A potential impact of advancing technology on cardiac surgery is demonstrated by Shivamurthy and colleagues. ${ }^{1}$ Their study of 15 patients suggests that leadless pacemakers can ultimately eliminate complexity of single-chamber ventricular (VVI) pacing after valve replacement. High points include claims of rapid, reliable implementation of pacing, favorable reduction of intensive care unit length of stay, and low complication rates. Surgeons who have struggled with VVI pacing after a long surgical case can readily appreciate the benefit of eliminating nests of wires and externally appended/connected electronics. ${ }^{2}$

The data presented seem to support the authors' case, yet the follow-up is incomplete. Thus, we would like to know the evolution of pacing thresholds at 1 year and related impacts on longevity of the pacing system and the cost of battery replacement, including device extraction. A properly constructed clinical trial would also include an appropriate control group for randomized comparison.

It is important to appreciate as well that VVI pacing is inappropriate for patients requiring atrioventricular synchrony and that implants during reoperations may have unpredictable results. Also, it is not always possible to predict preoperatively which patients will actually require permanent pacing. Thus, global implementation of VVI pacing

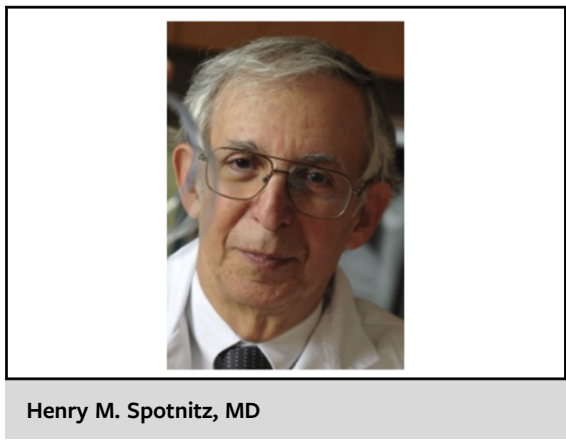

CENTRAL MESSAGE

Benefits of leadless pacemakers.

will not be cost effective or medically appropriate in every patient.

Nevertheless, this clinical research anticipates a time when leads and electronics are routinely integrated into a single package, with great benefits for patients and physicians. Further technical advances might include power supplied by circulating substrates and leadless multichamber defibrillators and pacemakers. This study of leadless pacemakers represents an advance toward a bright future for intraoperative implantation of a new generation of arrhythmia control devices.

\section{References}

1. Shivamurthy P, Miller MA, El-Eshmawi A, Boateng P, Pandis D, Pawale A, et al Leadless pacemaker implantation under direct visualization during valve surgery. J Thorac Cardiovasc Surg. 2022;163:1818-25.

2. Spotnitz MD, Spotnitz HM. Surgical Implantation of Pacemakers and Automatic Defibrillators in Lawrence H. Cohn Cardiac Surgery in the Adult. 5th ed. New York: McGraw Hill; 2018.

\footnotetext{
From the Cardiothoracic Surgery Division, Department of Surgery, Columbia University, New York, NY.

Disclosures: The author reported no conflicts of interest.

The Journal policy requires editors and reviewers to disclose conflicts of interest and to decline handling or reviewing manuscripts for which they may have a conflict of interest. The editors and reviewers of this article have no conflicts of interest.

Received for publication Aug 5, 2020; revisions received Aug 5, 2020; accepted for publication Aug 5, 2020; available ahead of print Aug 8, 2020.

Address for reprints: Henry M. Spotnitz, MD, Cardiothoracic Surgery Division, Department of Surgery, Columbia University, 622 West 168th St, Vanderbilt Clinic 1010, New York, NY 10032 (E-mail: hms2@cumc.columbia.edu).

J Thorac Cardiovasc Surg 2022;163:1827

$0022-5223 / \$ 36.00$

Copyright (c) 2020 by The American Association for Thoracic Surgery

https://doi.org/10.1016/j.jtcvs.2020.08.012
} 